\title{
Research on Some Questions of Inter-esterification of Oils and Fats
}

Oltiev $\mathrm{AT}^{*}$ and Majidov KH

Bukhara Engineering and Technological Institute, Bukhara City, Uzbekistan

\begin{abstract}
Development of methods of reception and the organization of industrial production of food plastic fats with balanced fatty-acid structure lowered to natural level by the maintenance of trance-isomerized acids at the optimum maintenance of irreplaceable linoleic acid is one of the actual problems which decision provides the further scientific and technical progress of fat-processing industries.
\end{abstract}

Keywords: Cotton oil and products of its processing; Cotton palmitin; Inter-esterification fats; Technology of their manufacture

\section{Introduction}

The scientific essence of the problem consists in research of advanced methods of modification of natural fats and oils, allowing to keep basic biologically important components of food fats in native condition and to ensure plastic mixtures of triglycerides in which the basic structuring components are triglycerides of saturated fat acids. Scientific work is directed on creation of universal technology of food plastic fats reception with adjustable acid and triglyceride structure and optimum physical and chemical indicators on the basis of purposeful application of statistical interesterification of fats [1].

\section{Materials and Methods}

Interesterification of oils, fats and modeling mixtures have been carried out in closed temperature-controlled reactor with volume of $0.1 \mathrm{dm}^{3}$, supplied with intensive mixer. The general concentration of sodium, concentration of active sodium alcoholate and sodium soaps in oil suspension estimated by methods of titration analysis. Activity of catalysts estimated on degree of interesterification of modeling mixtures. For research of chemical compound of the catalyst disintegration products were used selective extraction, gas-liquid and thin-layer chromatography and also nuclear magnetic resonance method. The maintenance of trans-isomershas been defined by the IR-spectroscopy method; division of triglycerides on molecular weight has been defined by the method of high-temperature gas-liquid chromatography; Research of distribution of fat acids in triglycerideshas been defined by the method of enzymatic hydrolysis with the subsequent calculation triglyceride structure [2-4]. Maintenance of monoesters of fat acids, mono- di- and triglycerideshas been defined by method of thin-layer and gas-liquid chromatography.

The polymorphic crystal structure of fat was analyzed by methodsXray diffraction and differential-thermal analysis.

\section{Results and Discussion}

Dynamics of redistribution of fat acids in molecules and between molecules triglycerides analyzed on modeling mixtures of liquid vegetable oils, hydrogenated fats with fusion temperature of $31^{\circ} \mathrm{C}$ to $65^{\circ} \mathrm{C}$, grease, palm-oil and palm stearin, differing by the various maintenance of saturated acids $\mathrm{CT}_{9}-\mathrm{CO}_{9}$. isomerized mono-nonsaturated acids and linoleic acids.

By method of lipase hydrolysis it is established that distribution of fat acids between extreme and average positions of glycerides changes gradually in process of interesterification, and ends with achievement offatty-acid structure identical to all positions equalto fatty-acid structure of an initial mixture of fats [3]. Fatty-acid structure of mono, di and triglycerides, monoester of fat acids and free fat acids present in interesterificated fat also answers to structure of initial fat that testifies to an equivalence of fat acids in process of interesterification, irrespective of their structure and an initial arrangement in molecules of triglycerides. The parity of symmetric and asymmetrical mono- and di-saturatedtriglycerides in mixture in process of interesterification continuously changes and in interesterificated fat reaches the quantity of 1:2 [5]. At interesterification of mixtures with identical fatty-acid structure the identical molecular structure of statistically interesterificated fat is reached, and change of triglyceride structure occurs gradually in process of interesterification and ends with formation of glyceride structure corresponding to statistical distribution of fat acids (Figure 1).

\section{Designations}

$\Pi_{3}, \Pi_{2} \mathbf{H}$ - mole rate of trisaturated and disaturated glycerides correspondingly, $\%$;

1, 2, 3-mixtures of cotton oil with the beef fat (60:40), palm stearin (58:42) and deeply hydrogenated fat (78:22) accordingly;

$\mathbf{N}_{01}, \mathbf{N}_{02}, \mathbf{N}_{03}$-triglyceride structure of initial fatty mixtures $1,2,3$ accordingly;

Apparently on Figure 1, during the selection of mixtures of defined fatty-acid structure and spending of interesterification to certain depth, it is possible to receive any triglyceride structure between structure of an initial mixture of fats and statistical distribution.

Points designate the structures of fat received by interesterification; the continuous line designates the structures received by mixture of initial and interesterificated fat. In practice reproducibility of partial interesterification is insufficient because of fluctuations of concentration of the catalyst, qualityof preparation of fatty raw materials, rather high speed of process and absence of express methods of the direct control

*Corresponding author: Oltiev AT, Bukhara Engineering and Technological Institute Bukhara City, Uzbekistan, Tel: +998916456684; E-mail: kafedra-03@mail.ru

Received April 04, 2016; Accepted April 22, 2016; Published April 28, 2016

Citation: Oltiev AT, Majidov KH (2016) Research on Some Questions of Interesterification of Oils and Fats. J Food Process Technol 7: 581. doi:10.4172/2157 7110.1000581

Copyright: $\odot 2016$ Oltiev AT, et al. This is an open-access article distributed under the terms of the Creative Commons Attribution License, which permits unrestricted use, distribution, and reproduction in any medium, provided the original author and source are credited. 
Citation: Oltiev AT, Majidov KH (2016) Research on Some Questions of Inter-esterification of Oils and Fats. J Food Process Technol 7: 581. doi:10.4172/2157-7110.1000581

triglyceride structure. It is established that mixturesof triglycerides, close on molecular structure to partially interesterificated fats, can be received by mixture of initial and interesterificated fatty mixture in certain parities. This variant of process is more favorable from the economic point of view too, because waste and fat losses in process interesterification are decreased [6]. It is shown that the major advantage of statistical interesterification of fats is possibility of reception of relatives on physical and chemical indicators interesterificated fats from the various fatty mixtures having identical group of fatty-acid structure. The basic physical and chemical indicators of these fats coincide within accuracy of methods of the analysis that is reasoned by close properties of mix-acidic triglycerides of palmitic and stearin acids, and also of oleic and linoleic acids.

For the first time is obtained systematized data characterizingdependence of physical and chemical indicators of interesterificated fats from their group fatty-acid and triglyceride of structure.

Influence of fatty-acid structure of interesterificated fat on fusion temperature, hardness and the maintenance of a firm phase at $15^{\circ} \mathrm{C}$ is shown on Figure 2. With increase of the maintenance of the highmolecular saturated fat acids (palmitic and especially stearin acids)

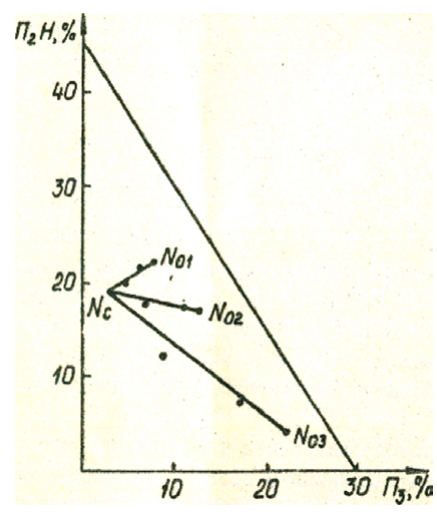

Figure 1: Statistical interesterification of mixtures of fats and oils with identical fatty-acid and various triglyceride structure (mole rate of saturated acids $\mathrm{C}_{16}-\mathrm{C}_{22}$ in initial fatty mixtures $\mathrm{N}_{01}=\mathrm{N}_{02}=\mathrm{N}_{03}=30 \%$ ).

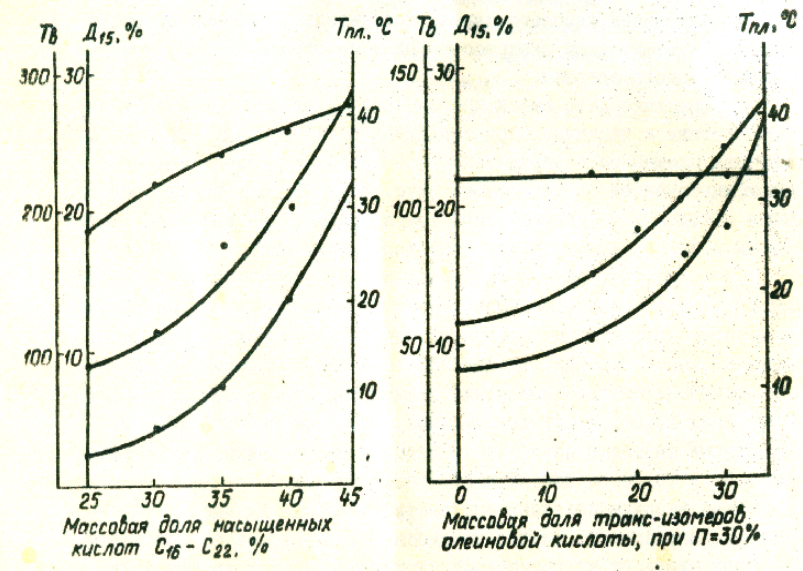

Figure 2: Dependence of physical and chemicalindicators ofinteresterificated fats from concentration of saturated fat acids $\mathrm{C}_{16}-\mathrm{C}_{22}$ and trance-isomerized acids.

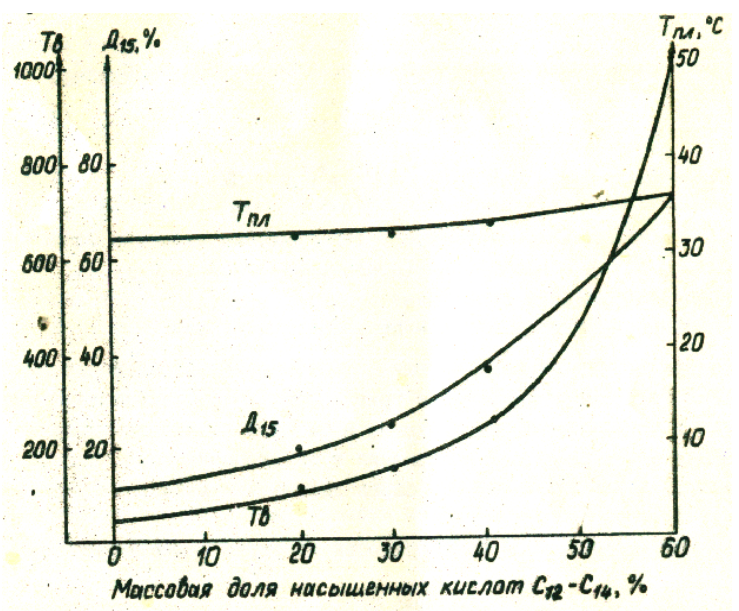

Figure 3: Dependence of physical and chemical indicators of interesterificated fats from concentration of saturated fat acids $C_{12}-C_{14}$ (at $\left.\Pi=30 \%\right)$.

from $25 \%$ to $45 \%$ the fusion temperature of interesterificated fat increases from $28^{\circ} \mathrm{C}$ to $41^{\circ} \mathrm{C}$. Hardness of interesterificated fat from 20 to $220 \mathrm{~g} / \mathrm{cm}$ and mass fraction of firm phase simultaneously rises at $15^{\circ} \mathrm{C}$ from $8 \%$ to $28 \%$. Parallel character of change of hardness and $\Pi_{15}$ shows to possible interdependence of these indicators.

At increase of the maintenance of trans-isomersof oleic acids from $0 \%$ to $35 \%$ against the constant maintenance of saturated fat acids $\mathrm{C}_{16}-\mathrm{C}_{22}(\Pi=30 \%)$ fusion temperature of interesterificated fat increases slightly, however essentially increases hardness (from $40 \mathrm{~g} / \mathrm{cm}$ to $120 \mathrm{~g} /$ $\mathrm{cm}$ ) and mass fraction of a firm phase at $15^{\circ} \mathrm{C}$.

Especially strong influence on properties of interesterificated fat is rendered by replacement of part of non-saturated fat acids with average-molecularsaturated acids $\mathrm{C}_{12}-\mathrm{C}_{14}$. In the fats, containing $30 \%$ of saturated fat acids $\mathrm{C}_{20}-\mathrm{C}_{22}$, at the increase maintenance averagemolecular acids from 0 to $60 \%$ the fusion temperature increases from $32^{\circ} \mathrm{C}$ to $36^{\circ} \mathrm{C}$, hardness from $40 \mathrm{~g} / \mathrm{cm}$ to $1000 \mathrm{~g} / \mathrm{cm}$, mass fraction of firm phase at $15^{\circ} \mathrm{C}$ from $11 \%$ to $71 \%$ (Mass concentration of saturated acids $\mathrm{C} 12-\mathrm{C} 14 \%$ (Figure 3)).

For the purpose of the quantitative descriptionof dependences between fatty-acid and triglyceride structure of interesterificated fats and their major physical and chemical indicators we have representation about structuring triglycerides. Fat as a first approximation represents the heterogeneous diphasic system which liquid phase is formed fused triglycerides. The firm phase of this system is formedby triglycerides which at the given temperature are insoluble or partially soluble in a liquid phase (structuring glycerides).

At each temperature structure of structuring triglycerides is different, depending on temperature of their fusion and solubility in a liquid phase of system. Compounding of interesterificated fats for physiological tests on fatty-acid structure intended as for foodof young, growing organism, and for food of patients with infringements lipidic metabolism [7]. Liquid vegetable oils of linolic-oleic groups with close to statistical distribution of fatty acids were entered into compounding, that provided similar distribution of linoleic acids in initial fatty mixture. Because of this after interesterification was reached not only preservation of the general level of linoleic acids, but also its concentration in physiologically important $2^{\text {nd }}$ position of triglycerides (Table 1). 
Citation: Oltiev AT, Majidov KH (2016) Research on Some Questions of Inter-esterification of Oils and Fats. J Food Process Technol 7: 581. doi:10.4172/2157-7110.1000581

\begin{tabular}{|l|c|c|}
\hline Structure of initial mix of fats and oils & \multicolumn{2}{|c|}{$\begin{array}{c}\text { Concentration of linoleic acids in } \\
\mathbf{2}^{\text {nd }} \text { position of triglycerides, } \%\end{array}$} \\
\cline { 2 - 3 } & $\begin{array}{c}\text { Before inter- } \\
\text { esterification }\end{array}$ & $\begin{array}{c}\text { After inter- } \\
\text { esterification }\end{array}$ \\
\hline Mutton fat & 3.5 & 3.5 \\
\hline Cotton oil & 39.0 & 33.6 \\
\hline Mutton fat + Cotton oil (50:50) & 19.0 & 17.7 \\
\hline $\begin{array}{l}\text { The hydrogenated and natural cotton oil } \\
\text { (50:50) }\end{array}$ & 12.2 & 11.6 \\
\hline $\begin{array}{l}\text { The hydrogenated cotton oil + mutton fat } \\
\text { + natural cotton oil (55:15:30) }\end{array}$ & 11.5 & 11.8 \\
\hline
\end{tabular}

Table 1: Influence of statistical interesterification of mixtures of fats and of oils on concentration of linoleic acids in $2^{\text {nd }}$ position of triglycerides.

Soft temperature conditions of interesterification of fats on sodium alkoxydes $\left(60^{\circ} \mathrm{C}\right.$ to $\left.90^{\circ} \mathrm{C}\right)$ and rather low dosages of the catalyst $(0.2 \%$ to $0.3 \%$ ) allow keeping biologically important components of food fats in native condition. It is established that in process of interesterification free sterols almost completely etherified byfat acids of triglycerides, but it does not reducebiological value of sterols. There is also considerable decrease in concentration of tocopherols (50\% from initial level), however this decrease much lower than at hydrogenation of fats [4]. At the contact of fat with sodium alkoxydes there will be destruction hydroperoxide connections which maintenance is decrease in 5-6 times. Deep clearing of fatty raw materials of oxidation products provides stability increase of interesterificated fats at the storage.

\section{Conclusion}

Analysis of the literary information and industrial production of margarine has shown that for radical improvement of quality and biological valueof mass kinds of margarine production, expansions of its raw-material base, the organization of manufacture of dietary margarine, products of a children's food, soft and bar margarine of sandwich-type are necessary plastic food fats with balanced fattyacid structure, lowered to natural level by the maintenance of transisomerized acids at the optimum maintenance of irreplaceable linoleic acid.

In work is offered advanced technology of updating of naturalfats and oils, allowing to keep in native condition the basicbiologically important components of fatty raw materials and to ensure some plastic food fats in which the basic structuring components are triglycerides of the saturated fat acids.

On the basis of consideration of plastic fats as solution of highmeltingtriglycerides in liquid fraction laws of change of physical and chemical indicators of plastic mixtures triglycerides at change of their molecular structure are theoretically proved. Correlation between group of triglyceride structure and the major physical and chemical indicators (fusion temperature, hardness, a mass fraction of a firm phase in the range of temperature $0^{\circ} \mathrm{C}$ to $40^{\circ} \mathrm{C}$ ) of statistically interesterificated fats and their mixtures is experimentally confirmed.

The obtained data was theoretical base for formationof fatty bases of margarine production with the set properties and substantiations of chemical-technological requirements to interesterificated fats for manufacture of margarine, culinary, baking fats and other food stuff.

Methods of calculation of componential structure of fatty basesreceived by mixture of fats of known glyceride structure and partial interesterification of fatty raw materials are developed. Process of interesterification of triglycerides at presence of sodium alkoxydes is analyzed and influence of technology factorson speed of intramolecular and intermolecular migration of acyls of fat acids in triglycerides is estimated. The treatment of process of interesterification of fats as chain non-ramified heterolytic reaction is offered, in which the active center conducting the chain of interesterification is sodium glyceroxyde.

The phasic mechanism of chain process is analyzed. It is established that the stage of chain origin represents reversible reaction of initial sodium alkoxyde with triglycerides, kinetic laws are analyzed, and the constant of balance and energy of activation of this reaction is defined. It is shown that distribution of the active centers of sodium glyceroxyde in mixture of triglycerides carries the statistical property. Kinetic laws are analyzed and the mechanisms of collateral nucleophilic reactions of splitting of sodium glyceroxyde are offered. It is established that the stage of interesterification represents the complex of reversible reactions of $2^{\text {nd }}$ order. Principles of selectionof models and condition of carrying out of the reaction are offered, allowing to provide a quasistationary state of chain process and to receive the kineticequation of the pseudo-first order. Kinetic laws of reaction of interesterification are analyzed and optimum parameters of process at production conditions are proved.

\section{References}

1. Arutyunyan NS, Kornena EP, Yanova LI (1999) Technology of processing of fats. Pishepromizdat.

2. Akramov OA (2008) Modification of cotton oil on effective catalysts. Tashkent TCTI.

3. Minzdrav (2002) Hygienic requirements of safety and food value of foodstuff Sanitary and prophylactic instructions and norms.

4. Stopskiy VS, Klyuchkin VV, Andreev NV (1992) Chemistry of fats and products of processing of fatty raw materials. Kolos.

5. Tyutyunnikov BN, Gladkiy FF (1992) Chemistry of fats. Kolos.

6. Perkel RL (2000) Modern problems of interesterification of oils and fats. Development of fat-and-oil complex of Russia in the conditions of market economy. All-Russian conference, Moscow.

7. Shenfeld T (2002) New methods of fat refining. Texizdat. 